\title{
A PROFILE OF SELECTED PSYCHIATRIC OUT-PATIENTS IN SOUTH AFRICA
}

\author{
LR Uys, NK Dlamini and SP Mabandla
}

\begin{abstract}
SUMMARY
This article reftects the results of three studies done between 1988 and 1991 describing psychiatric outpatients in different towns and cities of South Africa. Two of the samples consist of Black patients and one of Asian patients. In all three studies demographic, socio-econamic and illness data were gathered and analysed A total of 230 patients were surveyed.
\end{abstract}

The typical psychiatric outpatient seems to be in productive period of his life, single, but living with family. He is poorly educated. may never have been employed and is probably now unemployed. The income of this person and the household is very limited, with many peopte dependent on the few ecomonically active members of the househotd.

The person probably has a diagnosis of schizophrenia, epilepsy, depression or substance abuse. If Black, he has been certified ond haspitalized at least once for a period of twelve weeks. The person is now attending the outpatient clinic regularly once a month.

The socio-economic handicap of these patients is highlighted in the article, as are the implications for families having to care for them. The organization of psychiatric services is addressed in terms of differences in hospitalization rates between different samples and short-comings in the follow-up system.

\section{INTRODUCTION}

Studies in the patterns of morbidity of psychiatric out-patients in this country have been very limited. Gillis et al.(1986) studied the admission and readmissions to one psychiatric hospital, and mental illness was mentioned in a study of the morbidity rates in the medical wards of a large urban general hospital (Benatar and Saven ,1985). Wyndham (1985 and 1986) also has focused attention on the mortality figures associated with suicide in the country. These studies shed little light on the psychiatric patients who make up the out-patient populations all over the country.

Epidemiological studies of psychiatric patients in Africa have focused mainly on hospitalized populations (Ihezue 1986, Abiodun 1988 and 1990) and community wide studies (de Jong, 1986, Cederblad and Rahim 1989). Khandelwal and Worknesh(1988) however, described a $100 \%$ sample of psychiatric out-patients in Ethiopia in which they looked at age, gender and diagnosis. They found that $62,8 \%$ of the patients were males, and $67,4 \%$ were aged $21-40$ years. The most common diagnostic categories were depressive neurosis $(22,4 \%)$ and anxiety state $(14,7 \%)$. Schizophrenia was sixth on the list representing $8,1 \%$. Bodenstam et al. (1990) quotes official Zanzibar statistics of the outpatient population of a mental hospital in which $40 \%$ of the patients were diagnosed as having epilepsy, $35 \%$ as having schizophrenia, and $7 \%$ as cases of neurosis or anxiety.

Anthony et al. (1990) summarises the findings of numerous North American studies on psychiatric out-patients. They state that the number of patients with long-term psychiatric disabilities in full-time or part-time open-market employment is between 10 and 15\%. Castaneda and Sommer (1986) sampled 350 USA outpatients in terms of the characteristics of their residential arrangements. They found that $32 \%$ lived in a boarding establishment, $23 \%$ at home, $17 \%$ were semi-independent and $13 \%$ were in nursing homes.

In Australia, Wijesinghe (in Fish, 1988) found that $72 \%$ of the out-patients at an urban psychiatric hospital had a diagnosis of functional psychosis and $83,3 \%$ of them lived with their families. Clearly the socio-economic status, illness behaviour and outcomes of psychiatric outpatients have not been described in any detail in the literature. Such information is surely of importance to clinicians and administrators, since this forms the basis of programme evaluation and planning.

\section{RESEARCH METHODOLOGY}

This article is based on three studies done between 1988 and 1991, describing surveys of different psychiatric out-patient groups in South Africa.

The first, carried out by Fish (1988) describes the outpatient population of an urban psychiatric hospital serving mainly the Asian community living in the city. She surveyed a $10 \%$ sample $(100)$ of patients attending the department, with data collected through an interview and a record review. She covered demographics, socio-cultural data and illness data in her survey.

The second study by Dlamini (1992) was done in another urban centre at two psychiatric clinics which serve the Black community. In this case a stratified random sample of 30 patients were selected out of the clinic population of 525 patients. Stratification was done according to gender and age. Seventy-three percent of her sample lived in rural areas, and the rest in the city. The survey included demographics, illness data and outcomes in the form of the functional status. Data were collected through a record review as well as an interview which included use of the Brief Psychiatric Rating Scale and the Life Skills Profile.

The last study was completed by Mabandla (1991) in Umtata in the Transkei, which is a small town serving a large rural area. The general hospital psychiatric outpatient department, serving mostly Black patients, was the focus of the study. Again a 10\% sample including 100 patients was involved, with half being new patients interviewed at their first visit. The majority of the patients (58\%) lived in the rural areas around the town. The survey covered demographics, illness data and a measure of stress experienced, using an adaptation of the Rahe scale.

\section{RESULTS}

\section{DEMOGRAPHIC CHARACTERISTICS}

Gender

In Fish's study (1988) $54 \%$ of the patients were males, in the Dlamini study (1992) 63\%, and in the Mabandla study (1991) 59\%. All three studies therefore show a preponderence of male patients in out-patient services. The 
TABLE 1. AGES OF PSYCHIATRIC OUTPATIENTS

\begin{tabular}{|lr|rrr|rr|}
\hline \multicolumn{2}{|c|}{ Fish $N=100$} & \multicolumn{2}{c|}{ Dlamini $N=30$} & \multicolumn{2}{c|}{ Mabandla $N=100$} \\
\hline Age & $\%$ & Age & No & $\%$ & Age & $\%$ \\
\hline $0-18$ & 5 & $0-19$ & 1 & 3 & $0-10$ & 6 \\
$9-24$ & 4 & $20-24$ & 1 & 3 & $11-15$ & 6 \\
$25-34$ & 17 & $25-29$ & 6 & 20 & $16-20$ & 14 \\
$35-50$ & 42 & $30-34$ & 5 & 17 & $21-30$ & 32 \\
$51-64$ & 20 & $35-39$ & 1 & 3 & $31-40$ & 23 \\
$65+$ & 12 & $40-44$ & 9 & 30 & $41-50$ & 6 \\
& & $45-49$ & 3 & 10 & $51-60$ & 7 \\
& $50-54$ & 1 & 3 & $61+$ & 6 \\
& $60-64$ & 1 & 3 & & \\
\hline
\end{tabular}

\begin{tabular}{|l|rrr|rrr|rrr|}
\hline \multicolumn{1}{|c|}{ TABLE II. MARITAL STATUS OF PSYCHIATRIC OUTPATIENTS } \\
\hline \multicolumn{3}{|c}{ Fish } & \multicolumn{3}{c|}{ Dlamini } \\
\hline & M & F & Total & M & F & Total & M & F & Total \\
\hline Single & 23 & 10 & 33 & 11 & 8 & 19 & 36 & 16 & 52 \\
Married & 13 & 8 & 21 & 4 & 1 & 5 & 13 & 5 & 18 \\
Separated & 2 & 2 & 4 & 1 & 1 & 2 & 4 & 4 & 8 \\
Divorced & 2 & - & 2 & 0 & 0 & 0 & 3 & 3 & 6 \\
Widowed & 0 & 2 & 2 & 0 & 4 & 4 & 0 & 5 & 5 \\
Customary & & & & & & & & & \\
$\quad$ Marriage & 0 & 0 & 0 & 0 & 0 & 0 & 0 & 4 & 4 \\
Living together & & & & & & & 3 & 4 & 7 \\
\hline Total & 40 & 22 & 62 & 16 & 14 & 30 & 59 & 41 & 100 \\
\hline
\end{tabular}

\begin{tabular}{|l|rrr|rrr|rrr|r|r|}
\hline \multicolumn{8}{|c|}{ TABLE III. GENDER AND LEVEL OF EDUCATION } \\
\hline & \multicolumn{3}{|c|}{ Fish } & \multicolumn{3}{c|}{ Dlamini } & \multicolumn{3}{c|}{ Mabandla } \\
\hline & M & F & T & M & F & T & M & F & T \\
\hline Never attended & 3 & 7 & 10 & - & - & - & 11 & 9 & 20 \\
Class A + B & 7 & 4 & 11 & 2 & 4 & 6 & 10 & 3 & 13 \\
St $1-5$ & 18 & 15 & 33 & 5 & 5 & 10 & 17 & 13 & 30 \\
St $6-8$ & 20 & 14 & 34 & 7 & 4 & 11 & 12 & 12 & 24 \\
St $9-10$ & 6 & 6 & 12 & 1 & 1 & 2 & 7 & 3 & 10 \\
Post matric & 0 & 0 & 0 & 1 & 0 & 1 & 2 & 1 & 3 \\
\hline Total & \multicolumn{1}{|c|}{100} & & & 30 & & & 100 \\
\hline
\end{tabular}

\begin{tabular}{|l|c|c|c|}
\hline \multicolumn{4}{|c|}{ TABLE IV. HOUSING OF OUTPATIENTS } \\
\hline & FISH & DLAMINI & MABANDLA \\
\hline Alone & 2 & 3 & 3 \\
Old age home & 1 & 21 & 82 \\
Family (total) & 93 & 42 & 15 \\
$\quad$ family of origin & & 2 & 18 \\
$\quad$ nuclear family & & 2 & 7 \\
$\quad$ extended family & & 1 & 15 \\
children & & 6 & 100 \\
\hline Boarding & 4 & 30 & \\
\hline
\end{tabular}

percentages consistently are higher than the representation of male adults in the general population, which is $50,2 \%$ (Erasmus, 1991). This conforms with other African studies and contrasts with European studies (Ihezue 1986). Ihezue (1986) for example, speculates that the lower rates in females might be related to the difference in roles between men and women, with expectations of men being higher and women being buffered by their more submissive and less stressful lifestyle.

\section{Age}

All three studies used different age categories. The spread across these categories are summarized in Table 1 . The out-patient services clearly are used almost exclusively for adults, even though the psychiatric/mental health services for children outside of these services are almost non-existent for the Black communities. In the adult group the largest proportion of patients fall into the productive age group between 25 and 64 years. In the Fish's study (1988), which concentrated on the Asian community, this percentage is $79 \%$, while the corresponding percentage for the whole Asian population is 50\% (Medical Research Council, 1991). In Dlamini's study (1992) of Black patients the percentage is $86 \%$, while the percentage of this age group in the Black population is $42 \%$.

\section{Marital status}

The majority of patients in all of these groups are single, as shown in Table 2. The Asian group studied by of Fish (1988) shows a much higher proportion of married people than do the two Black groups. In Chavetz's North American study (1988), the percentage of married patients $(7,9 \%)$ is much lower than in Fish's [21\%] and Mabandla's [18\%] samples. It has been speculated that these statistics indicate the inadequacy of the premorbid personalities of the patients, but lower utilization of services by married persons due to the support of families might also cause this pattern.

\section{Educational Level}

With regard to the educational level summarized in Table 3, the differences between men and women were not significant in any of the studies. However, Fish (1988) points out that women with little schooling form a very large majority in the Asian group The percentage of illiterate patients (falling into the lowest two groups on the table) is over $20 \%$ in all three groups and some of the patients in the next category might also be functionally illiterate. The patients' rates therefore correspond roughly with the literacy rate of $70,1 \%$ which has been quoted for the Natal region and the $66,2 \%$ quoted for The Eastem Cape into which Mabandla's (1991) study falls (Erasmus, 1991).

\section{Housing}

The percentage of patients staying with their 
families is over $70 \%$ in all three studies, with the Asian group of Fish as high as $93 \%$ (see Table 4). This is much higher than the USA figure of 23\% given by Castaneda and Sommer (1986) and is more in accordance with Wijesinghe's (in Fish, 1988) figure of 83\% for Australia. In the case of South Africa, this high percentage of patients living with their families may reflect both the prevelance of intact extended family systems in both the Asian and Black communities, as well as the lack of housing alternatives for these groups.

\section{Employment status and income}

In Fish's group, $60 \%$ of the patients were receiving Disability Grants, and $9 \%$ received the Old Age Pension. Only $5 \%$ were employed in any way. The unemployment rate for the general population in this part of the country is $19,2 \%$, which shows the severe disability of the psychiatric outpatients in the field of employment (Erasmus, 1991).

Dlamini did not look at patients individually, but investigated income and employment per household. She found that only 15 households $(50 \%)$ had at least one person in the household working. Twenty-seven households (90\%) had a person receiving a Disability Grant, but this number includes 12 households in which two persons were receiving a grant or pension, and three households in which three persons were receiving a grant. It was found that the patients had an average of 4,5 children. Although the exact ratio cannot be calculated from the data reported, these figures lead one to expect a higher dependency ratio than that of the general population in this area, which is 2,8. This means that every person who is economically active (whether employed or unemployed) supports 2,8 people other than him/herself (Erasmus, 1991).

In Mabandla's group only $17 \%$ of the patients were receiving a Disability Grant. The lower percentage of patients in this group receiving financial assistance from the state might be related to the fact that they live in a self-governing "homeland". As far as their employment histories $\mathrm{go}, 42 \%$ have never been employed, while $66 \%$ are currently unemployed. Again this percentage is much higher than that of the general population in this area $(24,7 \%)$, even though the financial support for these patients is so poor (Erasmus, 1991).

\section{ILLNESS AND TREATMENT}

\section{Diagnosis}

In all three studies the diagnoses recorded in the patient records were used, without any attempt to find out whether these were valid according to current diagnostic systems. These working diagnoses show schizophrenia and depression as the main problems in the Asian community, and schizophrenia and epilepsy in the Black group in Natal.

In the Transkei sample the diagnosis of

\begin{tabular}{|c|c|c|c|c|c|c|c|c|c|}
\hline \multirow{2}{*}{ 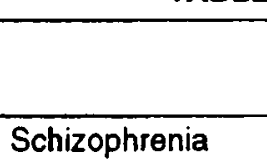 } & \multicolumn{3}{|c|}{ Fish } & \multicolumn{3}{|c|}{ Dlamini } & \multicolumn{3}{|c|}{ Mabandla } \\
\hline & $\mathbf{M}$ & $\mathbf{F}$ & $\mathbf{T}$ & $\mathbf{M}$ & $\mathbf{F}$ & $\mathbf{T}$ & $\mathbf{M}$ & $\mathbf{F}$ & $\mathbf{T}$ \\
\hline $\begin{array}{l}\text { Schizophrenia } \\
\text { Bipolar Affective } \\
\text { Disorders }\end{array}$ & 33 & 12 & 45 & 10 & 6 & 16 & 12 & 6 & 18 \\
\hline $\begin{array}{l}\text { Epilepsy } \\
\text { Behaviour } \\
\text { disorders }\end{array}$ & 6 & 3 & 9 & 4 & 6 & 10 & 23 & 9 & 32 \\
\hline Depression & 3 & 17 & 20 & 1 & 1 & 2 & 2 & 11 & 13 \\
\hline $\begin{array}{l}\text { Anxiety states } \\
\text { Organic Brain }\end{array}$ & 1 & 3 & 4 & & & & 2 & 2 & 4 \\
\hline $\begin{array}{l}\text { Syndrome } \\
\text { Developmental } \\
\text { disorders }\end{array}$ & 5 & 1 & 6 & & & & 1 & 5 & 6 \\
\hline $\begin{array}{l}\text { Substance abuse } \\
\text { Brief Reactive } \\
\text { Psychosis } \\
\text { Other and dual }\end{array}$ & & & & 1 & 0 & 1 & $\begin{array}{r}13 \\
4 \\
3\end{array}$ & $\begin{array}{l}2 \\
1 \\
4\end{array}$ & $\begin{array}{r}15 \\
5 \\
7\end{array}$ \\
\hline Total & 55 & 45 & 100 & 16 & 14 & 30 & 60 & 40 & 100 \\
\hline
\end{tabular}

schizophrenia is far less common. Even if Brief Reactive Psychoses is added, it still comprises only $20 \%$ of the sample. As compared to the Black group of Dlamini (1991), this group has a high percentage of both substance abuse and depression. One can only speculate about the possibility that the Umtata diagnoses, which show much more variety, are more accurate, but why this should be so is not clear.

\section{Hospitalization}

Only the first two studies looked at the hospitalization record of the patients. The number of admissions is summarized in Table 6 , and shows that in the Black group most patients get hospitalized once, while in the Asian group most are treated only on an out-patient basis. This difference may be the result of the greater rural component in the Black sample, and the lack of integration of psychiatric services in the primary health services. Thus the urban patients might have greater access to psychiatric community services, which makes it unneccessary for them ever to be hospitalized. The difference might also be related to the high incidence of epilepsy in the Black group, which might neccesitate hospitalization.

\begin{tabular}{|l|r|r|}
\hline \multicolumn{3}{|c|}{ TABLE VI. NUMBER OF } \\
HOSPITALIZATIONS \\
\hline \multicolumn{1}{|c|}{ Fish } & Dlamini \\
\hline None & 70 & 8 \\
1 & 10 & 13 \\
2 & 9 & 5 \\
3 & 6 & 3 \\
4 & 1 & 1 \\
$5+$ & 2 & 0 \\
Total & 98 & 30 \\
\hline
\end{tabular}

Dlamini also looked at the duration of admissions, and found that about $27 \%$ of admissions were for less than a week, 27\% was for between one and four weeks, $20 \%$ for between five and 12 weeks and the other $27 \%$ admissions were for longer than 13 weeks.

The majority of patients admitted (82\%) were certified, and only three were admitted as voluntary patients.

\section{Clinic attendance}

Mabandla investigated the route the patients followed to arrive at the clinic. She found that $19 \%$ were self-referred, $30 \%$ were brought by their families, and $26 \%$ were sent by a clinic or another section of the outpatient service. Traditional healers $(5 \%)$, general practitioners $(7 \%)$ and friends $(6 \%)$ also played a part in referral.

Table 7 shows that the Asian group has been attending the clinic for a shorter time than the Black group. where only about $27 \%$ of the sample has been clinic attenders less than five years. In Fish's group (1988), 77\% of the patients attended the clinic regularly on a monthly basis without missing a single month during the last year. In Dlamini's study (1992), the perfect attenders made up $53 \%$ of the group, while $33 \%$ missed two or more

TABLE VII. CLINIC ATTENDANCE

\begin{tabular}{|l|r|c|}
\hline Years & Fish & Dlamini \\
\hline $0-0,9$ & 8 & \\
$1-1,9$ & 4 & \\
$2-2,9$ & 16 & 8 \\
$3-3,9$ & 13 & \\
$4-4,9$ & 6 & \\
$5+$ & 5 & 3 \\
$10+$ & - & 19 \\
\hline
\end{tabular}


appointments. Since about the same number of patients paid more than R5 per visit for transport to and from the clinic, this might be a factor in their missed visits. Seventy-three percent of the patients always attended the clinic unaccompanied.

\section{PROFILE}

The typical psychiatric outpatient seems to be in the productive period of his life, single, but living with family. He is poorly educated, may never have been employed and is probably now unemployed. The income of this person and the household is very limited, with many people dependent on the few economically active members of the house hold.

The person probably has a diagnosis of schizophrenia, epilepsy, depression or substance abuse. If Black, he has been certified and hospitalized at least once for one to twelve weeks. The person is now attending the outpatient clinic regularly once a month.

\section{DISCUSSION}

The gender distribution and age distribution is similar to the Ethiopian study of Khandel whal and Worknesh (1988). These statistics highlight the economic implications of mental illness, with the person being incapacitated during a life stage characterized by economic activity, and in the person who is usually specifically seen as the breadwinner.

The social and economic handicap of these patients is further illustrated by the proportion who are single and unemployed. The high average number of children is seen by Dlamini as a way in which the patients try to achieve or to strengthen relationships. The Transkei group has a significantly better employment record than that of the better supported Asian group and the average USA figures (Anthony, Cohen and Farkas, 1990).

The solution to the rehabilitation dilemma therefore does not lie only in making Disability Grants more freely available. It might be the best solution to put the allocation of Disability Grant in the hands of the health system instead of the welfare system and to make their allocation more flexible, so that they can be used to enhance rehabilitation.

Most of these patients live with their families. In the Transkei sample this must cause financial hardship to the families, since so few of the patients receive Disability Grants. But even in the other families the stress of caring for a mentally ill family member over many years must be significant. Since most of the families do not attend clinics with the patients, the contact between them and the potentially helpful professional staff seems limited. Patients are cared for by these totally unprepared people most of the time, it falls to the health care workers to assist them and especially by giving structured and appropriate teaching.
The difference in hospitalization rates between the urban and urban/rural groups must make a strong case for incorporating psychiatric care in primary health care settings. At an average of 84 hospital days per patient and a cost of $R 120$ per patient per day (the average figures given for the hospital in question), this means that each hospitalization costs R10080. Multiply this by the number of outpatients seen in two of the clinics attached to this psychiatric hospital (525), and the amount climbs to R5 292000 spent on the hospitalization alone. Since $70 \%$ of the patients in the Fish sample were never hospitalized, it would mean a saving of R3 704 400 if this could be duplicated in the service Dlamini used. These amounts cover only two urban-rural clinics, and not the other clinics served by the same hospital.

The regular attendance of most patients can be seen as a golden opportunity for targeted psycho-social rehabilitaion programmes. However, not all patients needing out-patient treatment might be reaching the clinics. Solombela (1990) analyzed the patients discharged from a psychiatric hospital in the Transkei to a specific district over the period of one year. She found that only 140 of the 173 finally turned up at the clinic (80\%). According to the hospital records, $43 \%$ of the ones who turned up, were schizophrenic patients. The patients in this group may need a more intensive and systematic method of follow-up, such as case-management. Chavetz (1988) found in a North American study that the recidivist group tend to consist of young males, isolated from family, unemployed and with multiple problems. This group is probably unidentified in the three studies described in this article.

\section{REFERENCES}

ABIODUN, O.A. (1988). Morrality in a psychiatric population: A Nigerian psychiatric hospital experience. Acta Psych. 77, 654-657.

ABIODUN, O.A., OGUNREMI, O.O. (1990). Psychiatric morbidity in medical and surgical wards of a Nigerian general hospital Leumal of Esychosomalic Rescanch. 34(4), 409. 414.

ANTHONY, W., COHEN, M., FARKAS, M (1990). Psychiatric rehabilutation. Boston: Boston University.

BENATAR, S.R., SAVEN, A. (1985). Mortidity trends in the medical wands at Groote Schuur Hospital - 1971 and 1982. S.A. Medicalloumal 67, 968-969.

BODENSTAM, S., GARSSEN, J., ABDULWAKIL. A.I. (1990). Prevalence and treatment of mental disorders and epilepsy in Zanzibar. Aqu Psych Scand, 81, 327-331.

CASTANEDA, D., SOMMER, R. (1986). Patien housing options as viewed by parents of the mentally ill. Hespical and Communuy Psychiary 37(12), 1238-1242.

CEDERBLAD, M., RAHIM, S.I.A. (1989). A longitudinal study of mental health problems in a suburban population in Sudan. Acen Psjuch Scand. 79. 537-543.
CHAVETZ, L. (1988). Recidivist clients: a review of pilot data. Archives of Psychiatric Nursing. 2(1), 14-20.

DE JONG, J.T.V.M., de Klein, G.A.J., ten Hoom. S.G.H.H. (1986). A baseline study on mental disorders in Guine-Bissau. British Joumal of Esychiato, 148, 27-32.

DLAMINI, D.N. (1992). A profile of the psyctiatic outpatients in the Fort Napier hospital community services Unpublished MSocSc (Nursing) thesis, University of Natal, Durban.

ERASMUS, J. (Compiler 1991). Economic and social memorandum. Region E Johannesburg: Information Clearing House.

FISH, A.M. (1988). A descoption of a psyctiatic ourpatient population in an urban hospital Unpublished BSocSc Hons (Nursing) thesis, University of Natal, Durban.

GILLIS, LS., SANDLER, R., JAKOET, A., ELK, R. (1986). Admissions to a psychiatric hospital South African Medical Joumal. 70. 731 -734.

GILLIS, LS., SANDLER, R., JAKOET, A., ELK. R.(1986). Readmissions to a psychiatric hospital. South African Medical Joumal. 70. 735-739.

IHEZUE, U.H., KUMARASWAMY. N., ONUORA, A.N. (1986). Socio-economic status and mental disorder - profile of a Nigerian psychiar ric inpatient population. International Loumal of Social Psychiary, 32(1), 29-38.

KHANDELWAL, S.K., WORKNEH, F. (1988). Psychiatric outparients in a general hospital of Ethiopia : diagnostic and sociodemographic characteristics. The Intemational loumal of Socual Psychiary, 34(3), 230-235.

MABANDLA, F.S. (1991). A profile of psychiatic out-patients admilted in Umtata General Hospital psychiatric unit. Unpublished BS $\propto$ Sc Hons (Nursing) Thesis, University of Natal, Durban.

MEDICAL RESEARCH COUNCIL Changing heallh in South Africa: Lowards new perspectives in research (1991). Menlo Park Ca. The Henry, J. Kaiser Foundation.

SOLOMBELA, P.W. (1990). Eactors influencing the relapse of schizophrenic outpatients in the Kentani area of Tronskej. Unpublished MSocSc (Nursing) thesis, University of Natal. Durban.

WYNDHAM, C.H. (1985). Deaths from the mortality rates for largely preventable causes of death in whites in the RSA. South Afrocan Medical Joumal. 67.975-976.

WYNDHAM, C.H. (1986). Deaths from accidents, poisoning and violence - differences belween the various population groups in the RSA. South Afocin Medical loumal, 69, 556-558.

\section{LR UYS \\ Head of Department Nursing UNIVERSITY OF NATAL DURBAN}

NK DLAMINI

Community Psychiatric Services, Fort Napier Hospital, Pietermaritzburg

SP MABANDLA Umtata Nursing College 